DOI 10.37882/2500-3682.2021.12.16

\title{
КОММУНИКАЦИЯ В ГЛОБАЛЬНОМ МИРЕ: ЭКЗИСТЕНЦИАЛЬНО-ЦЕННОСТНЫЙ АСПЕКТ
}

\section{COMMUNICATION IN THE GLOBAL WORLD: EXISTENTIAL AND AXIOLOGICAL ASPECT}

E. Loginova

E. Grozdeva

Summary: The article is devoted to the study of communication in the context of the intensification of globalization. The authors focus on the existential and value aspect of communication, which importance especially increases at the present period of society development. The analysis of the concepts of such existential personalists as K. Jaspers, N.A. Berdyaev, E. Mounier shows their relevance for creating universal mechanisms of interaction and building an effective dialogue between people, states, nations and peoples based on the principles of consensus, understanding, tolerance and openness.

Keywords: existential communication, globalization, dialogue, value, communication.
Логинова Елена Геннадьевна

к.ф.н., дочент, Забайкальский институт железнодорожного транспорта - филиал Иркутского государственного университета путей сообщения elena_loginova@inbox.ru

Гвоздева Елена Николаевна к.п.н., доцент, Забайкальский институт железнодорожного транспорта - филиал Иркутского государственного университета путей сообщения gwelena@mail.ru

Аннотация: Статья посвящена исследованию проблемы коммуникации в условиях интенсификации глобализационных процессов. Авторы акцентируют внимание на экзистенциально-ценностном аспекте коммуникации, значимость которого особенно возрастает на современном этапе развития общества. Анализ концепций мыслителей экзистенциально-персоналистического направления К. Ясперса, Н.А. Бердяева, Э. Мунье показывает их актуальность для создания универсальных механизмов взаимодействия и построения эффективного диалога между людьми, государствами, нациями и народами на основе принципов согласия, взаимопонимания, толерантности и открытости.

Ключевые слова: экзистенциальная коммуникация, глобализация, диалог, ценность, общение.

экзистенциального отношения между людьми и о роли экзистенциально-ценностного компонента общения в эпоху глобальных социально-культурных преобразований. Рассмотрение этих вопросов требует использования диалектического, сравнительно-сопоставительного, дескриптивного и других научных методов.

Теоретической базой исследования послужили труды современных ученых и ведущих представителей русской и западно-европейской философии экзистенциализма. Практическая значимость работы основана на формировании мотивации к сохранению аксиологической составляющей процесса общения. Кроме того, исследование коммуникации в данном аспекте на фоне глобальной трансформации всех сфер жизнедеятельности общества может быть значимым дополнением к ее уже существующим научным теориям.

Необходимо отметить, что термин «коммуникация» довольно часто рассматривается исследователями и как частная разновидность общения, и как феномен, имеющий выраженные отличительные черты [7; 8; 9]. Актуализация того или иного понятия зависит от используемого в различных науках терминологического аппарата и поставленных в конкретных исследованиях задач. Без сомнения, при детальном рассмотрении между этими дефинициями обнаруживаются существенные 
различия, однако и общение, и коммуникация в широком смысле слова могут быть истолкованы в качестве целенаправленного взаимодействия людей, направленного на обмен информацией, мыслями, эмоциями, переживаниями. Именно такое толкование, без выделения принципиальных различий, отвечает целям настоящего исследования.

Коммуникация как важнейший фактор человеческого существования подвергается анализу как на уровне отдельно взятого индивида, так и на уровне социальной группы. В зависимости от того, кто является участником взаимодействия, выделяют три уровня общения: макро-, мезо- и микроуровень или соответственно массовая, групповая и межличностная коммуникации. Ряд авторов [16], исследуя коммуникативные особенности культуры, выделяют коммуникативный и метакоммуникативный уровни общения. Коммуникативный уровень подразумевает передачу информации. Непосредственное и опосредованное, вербальное и невербальное типы общения определяются в рамках данного уровня. Все эти виды отличаются конкретным характером воздействия. Метакоммуникативный уровень - это взаимодействие на основе информации, которая, как пишут авторы, «ушла в тень», но, тем не менее, обладает способностью оказывать влияние на глубинные пласты самосознания. Исходя из представленных авторами данных, можно сделать вывод, что при любом виде общения будет прослеживаться его метакоммуникативный характер, так как культурный фон, культурное наследие всегда будут, так или иначе, влиять на процесс коммуникации.

В свою очередь, глобализация, так же как и коммуникация, находится в эпицентре исследования самых разных научных направлений. В частности, Г. Макбруни, исследуя ее роль в формировании образовательной политики в системе высшего образования, пишет о том, что данный процесс происходит в четырех измерениях [19]. С ним солидарны многие современные авторы [5; 14], указывающие в качестве основных видов проявления глобализации ее экономическую, политическую, технологическую и социокультурную составляющие. Существуют попытки и более детальной классификации данного феномена, обозначающие индустриальный, финансовый, экономический, политический, информационный и культурный аспекты глобализации [10]. Таким образом, можно сделать вывод, что исследователи единогласно указывают на подверженность социокультурного компонента человеческого бытия процессу интеграции.

Анализ источников также показывает, что социокультурная сторона глобализации в первую очередь находит свое выражение в интенсификации коммуникации. J.W. Carey в своей работе «Communication as culture» пишет: «Основная ориентация в понимании коммуникации, глу- боко укорененная в нашем мышлении, есть идея трансмиссии: культура - это процесс передачи и распространения в пространстве сообщений под контролем людей» $[18$, c. 15].

Как упоминалось выше, активизация коммуникативных процессов в эпоху всеобщего глобализма привела к серьезным изменениям в сфере науки и образования, экономике, политике, искусстве и т.д. Так, стремление раскрыть потенциал коммуникативного подхода прослеживается в решении многих социальных проблем. На первый план выдвигаются такие ценности как толерантность, плюрализм, свобода, открытость и т.д. Коммуникативные знания и умения все больше признаются важнейшим компонентом в современной системе образования [15], поскольку общение, как ничто другое, оказывает влияние на социализацию личности, ее становление и формирование.

С другой стороны, хотя значение общения для отдельно взятого индивида трудно переоценить, при передаче информации при помощи современных технических средств всё меньше внимания уделяется ее получателям. Желание в кратчайшие сроки получить результат придает сообщениям директивный характер, что часто создает непонимание, влечет неправильную интерпретацию и порождает конфликтные ситуации. Виртуализация реальности в отдельных случаях приводит к полной утрате живого общения, и следовательно, потере собственной личности, собственного «я».

Перечисленные факторы заставляют нас обратиться к исследованию сущности понятия «коммуникации» в философии русского и западно-европейского экзистенциализма, так как именно в данном философском направлении обосновывается значимость экзистенциально-ценностного аспекта коммуникации.

Немецкий философ-экзистенциалист Карл Ясперс указывал в своих трудах, что коммуникация есть сущностная характеристика человеческого бытия. Путь к истинной экзистенции или подлинному существованию, по Ясперсу, возможен только через коммуникацию. Именно она является центром миропонимания мыслителя и «настолько составляет его [существования] всеохватывающую сущность, что все, что есть человек и что есть для человека ... обретается в коммуникации» [Цит. по: 6, с. 17]. Философ полагал, что настоящее общение - глубоко интимное и личностное - возможно только путем самораскрытия личности перед собеседником. Оно достижимо на основе полного доверия, осознании необходимости слышать и быть услышанным, понимать и быть понятым, и, возможно, на преобразовании ради этих целей самого себя. Таким образом, размышления Карла Ясперса, как и многих других мыслителей экзистенциальной направленности, основываются на утверждении, что движущей силой, пре- 
образующей мир и преобразующей каждого живущего в нем индивида, может быть только коммуникация, основанная на восприятии другой экзистенции как ценности, то есть коммуникация экзистенциальная [12].

Ясперс говорил и о вероятности глобальной коммуникации, подразумевая под этим единение людей всего мира. Движущей силой для создания связи между представителями разных народов и культур он считал философскую веру, которую определял в качестве осознания человеком своей экзистенции или уверенности в своей реальности, «встречу экзистенции и трансценденции» [17]. Философская вера в рассуждениях мыслителя сходна с верой религиозной, но последняя различается в зависимости от вероисповедания человека. Философская вера, напротив, всегда объединяет, потому что является общей для всех. Она создает истинное духовное единство, незримую экзистенциальную связь между народами.

В экзистенциально-персоналистической концепции русского религиозного мыслителя Н.А. Бердяева проблема общения предстает в свете его борьбы с бездушным объективированным миром [4]. Мир объектов противостоит человеческому «Я», которое чувствует себя покинутым, «заброшенным», одиноким. Объективированный мир - это мир бездуховности, где уникальность личности растворяется под прессом неопределенного безликого общего. Следствием процесса объективации Бердяев считал ограничение человеческой свободы и отрыв индивида от общества. Такая постановка проблемы общения в философии Бердяева позволяет заключить, что мыслитель предостерегает об утрате независимости и оригинальности личности при осуществлении ее включенности в мир на бездуховной основе [4].

По мысли Бердяева, каждое отдельно взятое «я» существует как некий микрокосмос, тайну и глубину которого невозможно разгадать и постичь в полной мере. Однако при истинном общении субъекты «я» и «ты» открываются перед друг другом и образуется единство «мы». Именно через отношение «мы» личность внедряется в общество и осознает свою «коммюнотарность»
[3]. Следовательно, выход из объективированного мира, прорыв к подлинному существованию философ видел в акте экзистенциальной коммуникации, ценность которой проявляется в признании уникальности другой личности, в стремлении к познанию ее внутреннего мира.

Французский философ-персоналист Э. Мунье, так же, как и Н. Бердяев, полагал, что только в состоянии открытости личности для «другого» появляются возможности и перспективы индивидуального существования. «Личность существует только в своем устремлении к "другому", - писал он, - познает себя только через "другого" и обретает себя только в "другом"» [13, с. 39]. Согласно теории Мунье, изначально личность сосредоточена в себе, но ее природа коммуникабельна, поэтому задача каждого индивида преодолеть свой эгоцентризм, раскрыть себя и обрести себя в другом. Чувство единения и духовной общности приобретается через взаимозависимость, экзистенциально-персоналистическое душевное общение, основанное на взаимопонимании, согласии, исключающее абстрактность и эгоизм.

Экзистенциальная концепция коммуникации приобретает особую значимость в эпоху глобализма, когда нации и народы должны искать пути для достижения согласия и взаимопонимания. Согласно взглядам современных ученых, «под транснациональной экзистенциальной коммуникацией можно понимать осуществление модели коммуникации Ясперса ради передачи транснациональных ценностей и смыслов во имя достижения согласия в мире и преодоления образов политического «врага»» [1, с. 132].

Таким образом, чрезвычайно сложные политические, экономические и социальные условия и психологический климат в современном глобальном обществе заставляют обратиться к проблеме общения как аксиологической категории. В этом контексте экзистенциальная коммуникация не только делает возможным осуществление простого диалога как акта общения, но диалога, построенного на принципах свободы, справедливости, разумности и толерантности.

\section{ЛИТЕРАТУРА}

1. Акопов С.В. Государство, глобализация и экзистенциальная транснациональная коммуникация // Политическая экспертиза: ПОЛИТЭКС. 2013. Том 9. № 4. C. 124-134.

2. Арсеньева И.И. Глобализация и перспективы мирового развития // Журнал Известия Российского государственного педагогического университета им. А. И. Герцена. 2008. №81. С.7-15.

3. Бердяев Н.А. Философия свободного духа. Проблематика и апология христианства // Бердяев Н.А. Философия свободного духа. М.: Республика, 1994. 479 с.

4. Бердяев Н.А. Я и мир объектов. Опыт философии одиночества и общения // Бердяев Н.А. Философия свободного духа. М.: Республика, 1994. 479 с.

5. Высотская А.Б. Влияние глобализации на национальные учетные системы развивающихся стран в условиях информационной экономики // Пространство экономики. 2014. №2. С. 109-116.

6. Гайденко П.П. Человек и история в экзистенциальной философии Карла Ясперса // Ясперс К. Смысл и назначение истории. М.: Политиздат, 1991. С. 5-26. 
7. Грачев В.И. Коммуникация и общение в современной культуре: уроки научной аберрации // Вестник Ленинградского государственного университета им. А.С. Пушкина. 2011. Т. 2. № 4. С. 229-236.

8. Гусева Д.И. «Коммуникация» и «общение»: соотношение понятий // Вестник науки и образования. 2019. №20 (74). С. 84-87.

9. Ерохин В.С., Ерохина Н.В. Коммуникация как социальный феномен // Манускрипт. 2021. Т. 14. № 3. С. 500-504.

10. Кручинин И.Н. Процесс глобализации: проблема неравенства в глобализации // Хроноэкономика. 2019. № 5. С. $64-69$.

11. Логинова Е.Г. Проблематика языка и общения в русской религиозной философии конца XIX - начала XX веков: социально-философский анализ // Гуманитарный научный вестник. 2021. № 3. С. 199-203. URL: http://naukavestnik.ru/doc/2021/03/Loginova.pdf

12. Логинова Е.Г., Гвоздева Е.Н. Язык и коммуникация в философии экзистенциализма: К. Ясперс и М. Хайдеггер // Контекст и рефлексия: философия о мире и человеке. 2020. Том 9. № 6А. C. 102-108. DOI: 10.34670/AR.2020.40.76.011.

13. Мунье Э. Персонализм. М.: Искусство, 1992. 142 с.

14. Пензина Е.В. Феномен глобализации: глобализация и вестернизация // Вестник КрасГАУ. 2012. № 8. С. $228-233$.

15. Середа Л.И. Коммуникативно-деятельностный подход в обучении иностранному языку в техническом вузе // Культура. Наука. 0бразование 2018. № 2 (47). С. 146-156.

16. Симонова М.М., Левченкова Т.А., Бутырина С.А. Коммуникативный характер культуры в ее развитии // Вестник славянских культур. 2019. № 1. С. 65-72.

17. Ясперс К. Философская вера // Ясперс К. Смысл и назначение истории. М.: Республика, 1994.

18. Carey J.W. Communication as culture. Boston, Unwin Human Publ., 1992. 302 p.

19. Macbruni G. Globalization as a political paradigm of higher education // Higher education today. 2001. no.1, pp. 46-53.

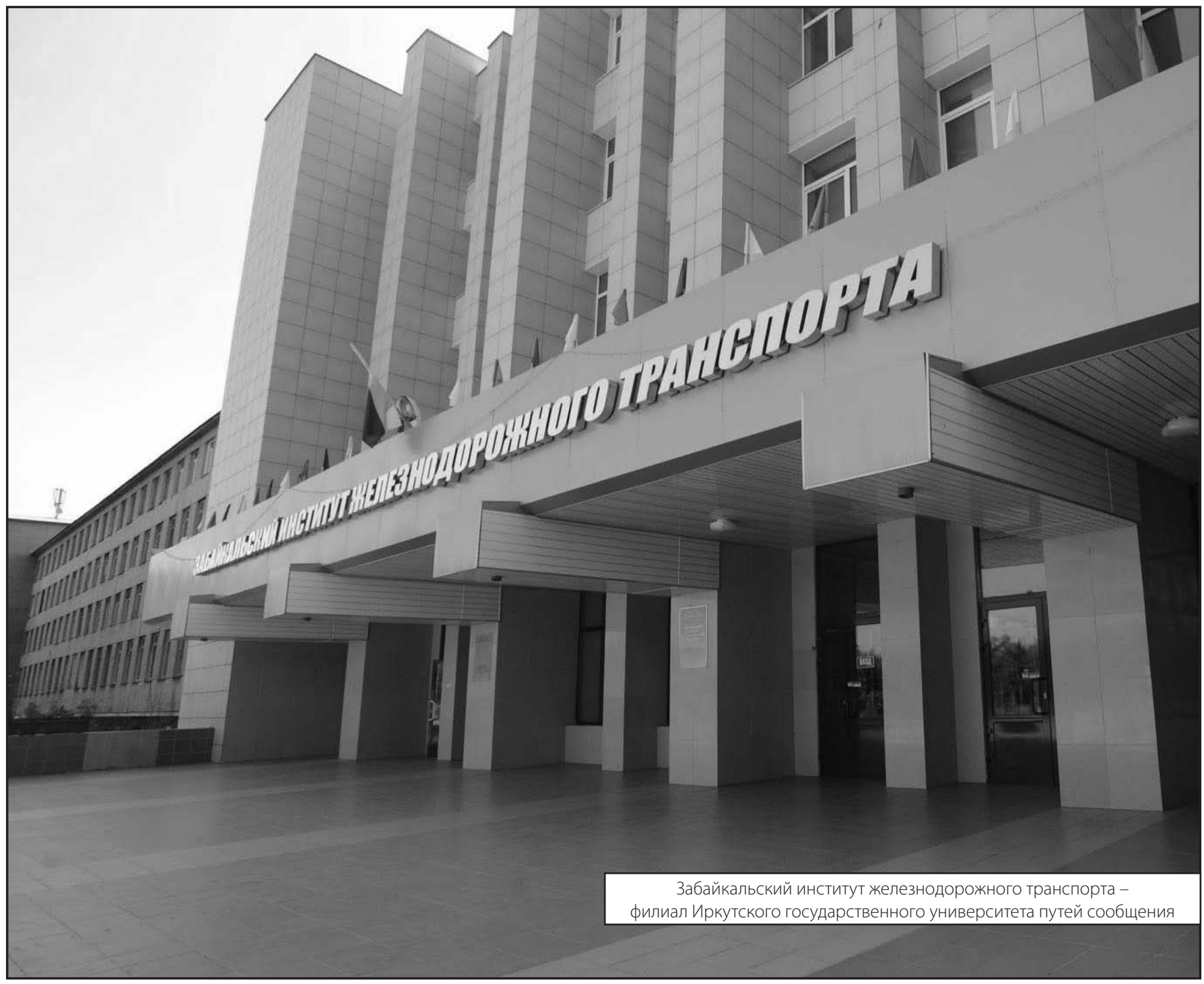

